\title{
Atenção a usuários de álcool e outras drogas e os limites da composição de redes
}

Care to users of alcohol and other drugs and the limits of network arrangements

Atención a consumidores de alcohol y otras drogas, y límites de la composición de redes

Laura Ferreira Cortes ${ }^{1}$, Marlene Gomes Terra², Fábio Becker Pires ${ }^{3}$, Juliane Heinrich ${ }^{4}$,

Katiusci Lehnhard Machado ${ }^{5}$, Teresinha Heck Weiller ${ }^{6}$, Stela Maris de Mello Padoin ${ }^{7}$

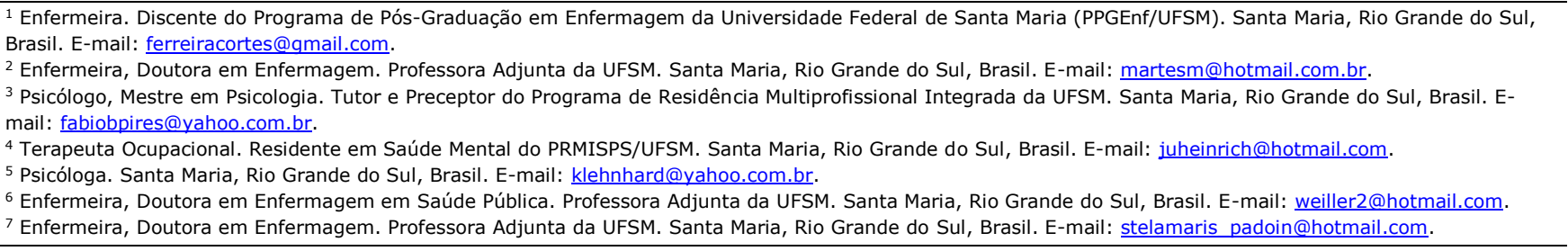

\section{RESUMO}

Pesquisa qualitativa objetivou compreender como se articulam os serviços de saúde mental, álcool e outras drogas a partir da compreensão de profissionais de saúde. Foi desenvolvido grupo focal com 10 profissionais de Estratégia de Saúde da Família em 2011. Na análise de conteúdo temática compreendeu-se que a desarticulação dos serviços de saúde mental é um fator limitante à composição da rede de atenção, bem como ao acesso aos serviços pelos usuários. As barreiras para o acesso são determinadas pela dificuldade de acolhimento nos serviços de saúde e reprodução do modelo hegemônico, que prioriza os encaminhamentos aos serviços especializados. A insuficiente qualificação para o trabalho em rede sinaliza limitações à atuação, apontando para a necessidade de apoio matricial em saúde mental. Destaca-se a urgência de repensar as práticas em saúde de modo a (re)organizar a maneira como os serviços se estruturam, visando à composição de uma rede em saúde mental.

Descritores: Saúde Mental; Atenção Primária à Saúde; Assistência à Saúde; Cuidados de Enfermagem; Transtornos Relacionados ao Uso de Substâncias.

\section{ABSTRACT}

The objective of this qualitative study was to understand the connections between the care services for mental health and users of alcohol and other drugs, considering the view of health care professionals. A focal group was developed with 10 Family Health Strategy workers in 2011. Thematic content analysis revealed that the disconnection between mental health care services is a limiting factor to the arrangement of the network, as well as to clients' access to services. Accessibility barriers are established by the difficulty that health care services have to embrace patients and their reproduction of the hegemonic model, which prioritizes referrals to specialist services. The insufficient qualification to work as a network reveals the workers' limitations, pointing at a need for matrix support in mental health. The urgency to rethink practices is highlighted as a way to (re)organize service structure, aiming at building a network for care in mental health.

Descriptors: Mental Health; Primary Health Care; Delivery of Health Care; Nursing Care; Substance-Related Disorders.

\section{RESUMEN}

Investigación cualitativa objetivando comprender la articulación de servicios de salud mental, alcohol y otras drogas, partiendo de la comprensión de profesionales de salud. Se desarrolló grupo focal con 10 profesionales de Estrategia Salud de la Familia, en 2011. El análisis de contenido temático expresó que la desarticulación de los servicios de salud mental constituye factor limitante para la composición de la red de atención, y para el acceso del consumidor al servicio. Las barreras de acceso resultan determinadas por la dificultad de recepción en los servicios de salud y por reproducción del modelo hegemónico, priorizándose las derivaciones a servicios especializados. La insuficiente calificación para trabajo en red determina limitaciones de actuación, determinando necesidad de apoyo matricial en salud mental. Se enfatiza necesidad de urgente reconsideración de las prácticas en salud para (re)organizarlas de acuerdo a la estructura de los servicios, a efectos de componer una red en salud mental.

Descriptores: Salud Mental; Atención Primaria de Salud; Prestación de Atención de Salud; Atención de Enfermería; Trastornos Relacionados con Sustancias. 


\section{INTRODUÇÃO}

Os pressupostos e diretrizes da Política Nacional de Atenção Integral a Usuários de Álcool e Outras Drogas (2003) estão em consonância com a Reforma Psiquiátrica, e com as propostas da Organização Mundial da Saúde ${ }^{(1)}$. As diretrizes para atenção pautam-se em estratégias que visam ao fortalecimento da rede de atenção aos usuários, com ênfase na reabilitação e reinserção social, centrada na atenção comunitária e na perspectiva de redução de danos. Nesse sentido, busca-se ampliação dos olhares acerca do uso abusivo de álcool e outras drogas, com vistas à superação da maneira reducionista de ver os usuários, muitas vezes, restringidos ao campo da marginalização e criminalidade. Faz-se necessário fortalecer políticas públicas com ações ampliadas e intersetoriais, que produzam diálogos sobre os desejos e projetos de vida dessas pessoas, a fim de produzir uma lógica nova na gestão do cuidado e proporcionar mecanismos de interlocução éticos, resolutivos, responsabilizando-se pelas demandas do território(2).

Entende-se que a rede de atenção pressupõe conexões e comunicações. Quando se pensa no desenho do itinerário que o usuário percorre em uma rede de saúde, incluímos a assistência social, entidades comunitárias, redes não necessariamente inseridas no sistema de saúde, mas que de alguma forma participam desta, garantindo assistência às necessidades de saúde do usuário(3).

O compromisso apontado pela Política é a garantia do direito ao tratamento, atenção humanizada e participativa aos usuários de drogas e suas famílias. Por sua vez, o compromisso da saúde e do SUS consiste em criar e manter equipamentos, qualificar profissionais, formular políticas de saúde em articulação com outras áreas, executar e avaliar tais políticas; fortalecer seu caráter de rede, incitando outras redes à conexão. Para tanto, é necessária a construção de vínculos, da corresponsabilidade e de uma perspectiva ampliada da clínica, a fim de transformar os serviços em locais de acolhimento e enfrentamento coletivo das situações ligadas ao problema(1).

A proximidade com as famílias, comunidades, possibilita que as equipes de Atenção Básica ( $A B$ ) sejam estratégicas na construção de ações voltadas para prevenção de agravos relacionados ao uso abusivo de álcool e outras drogas. Assim como, de diversas formas de sofrimento psíquico, uma vez que a saúde da família tem poder de inserção maior no território que os Centros de Atenção Psicossocial (CAPS) ${ }^{(4-5)}$.
No entanto, as concepções e práticas em saúde mental no nível primário de atenção à saúde nem sempre condizem com o esperado por parte dos que formulam a Reforma Psiquiátrica brasileira. Isto é reafirmado pelo Ministério da Saúde, quando expressa que apesar de importante a articulação da saúde mental com a atenção primária, "nem sempre esta apresenta condições favoráveis para realizar essa difícil tarefa; às vezes, pela falta de recursos, e/ou pela falta de capacitação que acabam por prejudicar 0 desenvolvimento de uma ação integral pelas equipes"(1). Colocam-se, então, em cena os processos de trabalho das equipes, a exemplo, as Estratégias de Saúde da Família (ESFs), onde, apesar das inúmeras contribuições na atenção à saúde, observa-se que a questão das drogas tem sido pouco abordada na prática profissional dos trabalhadores ${ }^{(6)}$.

Tendo em vista que descentralizar a Saúde Mental para os territórios foi uma conquista árdua para a Reforma Psiquiátrica, considera-se necessário aprimorar esse modelo, a fim de desenvolver uma clínica implicada com a constituição de sujeitos mais saudáveis em sua afetividade e em suas relações sociais, e mais potentes para transformar a realidade ${ }^{(7)}$. Nesse sentido, é fundamental destacar o papel dos Centros de Atenção Psicossocial-Álcool e Drogas (CAPS-AD), junto às equipes de $A B$ na articulação das ações desenvolvidas e no empoderamento daquelas, em especial as de ESF, a fim de subsidiar o trabalho com o tema proposto, fornecendo apoio especializado de referência, ou seja, apoio matricial ${ }^{(5,8)}$.

Este cenário gera questionamentos quanto à contribuição dos avanços na reinserção social e na não estigmatização dos sujeitos envolvidos com a problemática de álcool e outras drogas. Frente à importância dessa temática nas relações sociais e de saúde pública, justificase essa investigação, uma vez que acreditamos que os resultados obtidos possam gerar reflexões dos profissionais e gestores envolvidos sobre a questão das drogas, possibilitando um olhar diferenciado no que tange as relações entre profissionais e usuários. Além disto, a compreensão sobre a temática e a implicação desta nos serviços ressaltará a possibilidade de se buscar estratégias de trabalho em rede que englobem as questões de saúde, direitos e cidadania dos sujeitos, como forma de ir ao encontro do preconizado nas políticas públicas dirigidas a usuários de drogas.

Com base nessas questões, tal pesquisa objetivou compreender como se articulam os serviços da rede álcool e 
outras drogas, para uma equipe de ESF. Espera-se que este estudo propicie a ampliação da discussão crítico reflexiva sobre o tema e, assim, auxilie na construção de modelos de gestão participativa e na articulação de diferentes serviços e setores que alicerçam a rede de atenção aos usuários de álcool e outras drogas.

\section{MÉTODO}

Trata-se de um estudo com abordagem qualitativa desenvolvido em uma Unidade de Estratégia de Saúde da Família (UESF) do Município de Santa Maria, no RS. Essa abordagem permitiu a busca da compreensão das experiências humanas vividas pelos sujeitos do estudo, o que é possível a partir da descrição da experiência, tal qual ela é definida pelos mesmos ${ }^{(9)}$.

Constituíram-se, como sujeitos do estudo, 10 profissionais de saúde (sete agentes comunitárias de saúde, duas enfermeiras e uma técnica de enfermagem), escolhidos de maneira intencional, todas mulheres, com idade entre 25 e 53 anos, da referida unidade. Para a participação no estudo, elegeram-se os seguintes critérios: ser profissional da equipe de saúde da UESF, alocado no território, em contato direto com as famílias e comunidades, aceitar participar do estudo e não estar em licença de saúde no período da coleta de dados.

Para captação dos sujeitos foi realizado contato prévio, a fim de que fossem agendadas data e hora para a realização dos grupos focais. Ressalta-se que essa técnica de coleta recomenda que os integrantes apresentem traços comuns, embora seja necessária variação suficiente entre eles a fim de que as opiniões possam contemplar as diferenças. Para operacionalização, as reuniões são compostas de pequeno número de participantes, mínimo de seis e máximo de quinze, justificando-se assim o número de sujeitos neste estudo(10).

A UESF em questão faz parte do cenário municipal, que conta com 13 UESFs e 16 Unidades Básicas de Saúde. Os serviços especializados em saúde mental compreendem um Ambulatório Municipal de Saúde Mental, dois CAPS AD, um CAPS para transtornos psíquicos graves, um CAPS Infantil, um serviço de emergência psiquiátrica vinculado ao hospital geral público e à Unidade de Internação para Dependência Química, e outro hospital geral com leitos de saúde mental. Além disso, destaca-se o espaço de articulação e direcionamento da política de saúde mental, denominado Comissão de Saúde Mental.
A produção dos dados foi realizada nos turnos da manhã ou tarde, no período de outubro a novembro de 2011. Para assegurar o sigilo foi utilizado nos depoimentos um código com a letra $P$ (de "profissional") e numeral ordinário em ordem crescente. Foi utilizada a técnica do grupo focal, por propiciar a expressão de características psicossociológicas e culturais, e a exposição de um determinado tema por meio de sessões em grupo. Considera-se que possibilita um processo de interação grupal que acontece a partir trocas e descobertas oriundas de participações comprometidas, oportunizando aos participantes responderem às questões $\operatorname{propostas}^{(10)}$.

Os três grupos realizados contaram com a presença de duas observadoras, as quais realizavam as anotações dos principais pontos discutidos, e uma moderadora, que conduzia o encontro. Além de expor os objetivos e o funcionamento do grupo, a moderadora possibilitou ambiente propício à participação das profissionais. A fim de estimular a discussão, utilizaram-se fragmentos da Política

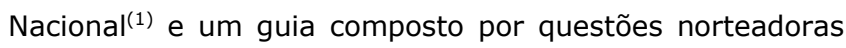
que versavam sobre o papel do Estado na Política sobre drogas; as ações de tratamento, recuperação e reinserção social de usuários de álcool e outras drogas.

Os dados obtidos foram transcritos para posterior análise temática, que se constituiu de três etapas: ordenação, classificação dos dados e análise final( ${ }^{(9)}$. Foram identificadas as ideias centrais e aspectos relevantes acerca da compreensão sobre a estrutura dos dispositivos da rede de atenção à saúde mental, para usuários de álcool e outras drogas da referida equipe de ESF, com o intuito de construir categorias empíricas. Para análise final, articulou-se o material estruturado ao referencial teórico, visando à identificação do conteúdo subjacente ao manifestado, na tentativa de responder às questões da pesquisa com base no objetivo. Realizou-se a categorização temática Atenção a usuários de álcool e outras drogas, sendo esta composta pelas subcategorias: Compreensão sobre a articulação dos serviços de saúde mental do município; e Limites de acesso ao tratamento.

Os aspectos éticos que envolvem investigação com seres humanos foram respeitados durante todo o trâmite da pesquisa, atendendo à Resolução no 466/2012 do Conselho Nacional de Saúde. O estudo foi aprovado pelo Comitê de Ética em Pesquisa da UFSM, sob parecer no 0241.0.243.000-11, no dia 27/09/2011. As profissionais aceitaram participar da pesquisa após a compreensão e 
concordância da exposição das questões éticas, assinando o Termo de Consentimento Livre e Esclarecido.

\section{RESULTADOS}

\section{Atenção a usuários de álcool e outras drogas e os limites da composição de redes}

Esta categoria reuniu dois temas relativos à compreensão sobre a dificuldade de articulação dos serviços de saúde mental, álcool e outras drogas, e os limites de acesso dos usuários ao tratamento. Destaca-se, a partir da insuficiente qualificação para o trabalho em rede, os limites da atuação profissional frente à articulação dos serviços, construção de redes e demandas de usuários. Isso sinaliza a premente necessidade de qualificação profissional e apoio matricial a fim de que sejam consolidadas ações resolutivas e de acolhimento aos usuários do serviço em questão no campo da saúde mental.

\section{Compreensão sobre a dificuldade de articulação dos serviços de saúde mental do município}

Dos depoimentos emergiram o desconhecimento acerca da organização dos serviços, comunicação ineficaz, desarticulação, inexistência de um fluxograma organizativo, necessidade de qualificação profissional em saúde mental e apoio matricial.

[...] Porque tu não tens pra onde enviar depois. Não tem mais continuidade ao trabalho com

o paciente. [...] Totalmente desarticulado. Antes, a gente tinha um fluxo. [...] Tu te sente

incapaz. (P2).

Entre os profissionais tá faltando uma comunicação, por exemplo, vai um surtado lá pro

hospital. [...] O psiquiatra que atende diz assim: "Eu Ihe dou essa medicação por 30 dias.

Em 30 dias a senhora tem consulta com o psiquiatra da rede", eles não tem noção que na rede tem um psiquiatra $(P 5)$.

Eu particularmente não conheço muito o serviço do CAPS [...] e nunca fui atrás para saber

como é que era [...]. O que falta é a contrarreferência (P7).

Ao mesmo tempo em que expressaram preocupação com a dificuldade em se comunicar com os serviços de saúde mental do município, as profissionais não se sentiam suficientemente capazes para realizar ações articuladas em rede e atribuíam esse fato à falta de capacitação técnica em saúde mental.

Como é que eu vou trazer um caso que é quase como uma bomba pra gente resolver no posto? Daí eu trago pra Enfermeira, e ela diz: "Vamos resolver com o pessoal de lá [CRAS] porque a gente não tem pernas" (P2).

Percebe-se que há um consenso nos relatos sobre a necessidade de apoio especializado, apoio matricial, para a gestão dos casos de saúde mental no território da $A B$, já que há necessidade de instrumentalização dos profissionais das equipes de referência.

Na gestão anterior, aconteciam aquelas rodas \{apoio de especialistas\}. Acontecia alguma coisa [...] pra gente aprender $[\ldots](P 2)$.

Falta o apoio matricial, aquela qualificação [...]. Isso, as drogas, já vem há anos, mas pra nós que trabalhamos é muito novo tudo $[\ldots](P 7)$.

\section{Limites de acesso ao tratamento}

As respondentes, ao refletirem sobre a composição de uma possível rede de saúde mental, apontaram para a dificuldade em ser resolutivas. Isso foi relacionado com as opções escassas de recursos para o tratamento, bem como com a desigualdade de acesso e de acolhimento dos usuários e familiares nesses serviços. Além de limitações quanto ao número de profissionais especialistas.

Relatos de pacientes dizem que tem mais de 1000 na fila de espera no ambulatório de saúde mental. Só tem que aguardar (P1).

O usuário de drogas tá que nem batata-quente [...], cada um vai passando pra um lado, porque ele tá pra lá, daqui a pouco ele tá na minha mão. Quando eu chego na casa dele, ele me pergunta, eu já não sei. Enrolo ele um pouco [...] e passo pra outro, deu! Não seria o correto [...]. A minha preocupação é pelos níveis sociais, tipo o que tem \{dinheiro\} vai pegar aquele filho usuário de droga e vai pra lá \{clínica\}. E aquele nosso usuário que é carente, ele fica por aí, ou ele morre (P2).

A gente chega nas casas e vê o desespero dos familiares e a gente não tem o que fazer [...]. O familiar não tem uma orientação, não tem nada [...] (P3). 
Eu achei meio vago quando ela \{usuária\} vem de lá $\{d a$ internação hospitalar\}, e diz assim: "ela \{profissional\} disse pra eu procurar o psiquiatra da rede". Tá mas o psiquiatra da rede que a gente sabe que não existe, né? E não tem que ter uma continuidade com a medicação? É isso que me deixou preocupada, porque daqui a pouco ela vai voltar pra lá \{internação\} de novo. (P4)

Poucos profissionais e muitos doentes. Psiquiatra é um que tá atendendo aqui pelo município e já tivemos sem psiquiatra. (P5)

A espera agrava a doença. [...] Uns têm \{acompanhamento\}, outros já não conseguem [...]. Nós dissemos assim pro familiar: quando ele entrar em surto, leva no hospital que lá o atendimento de emergência é só pra surtado [...]. Pra mãe internar um filho pra desintoxicação é só com ordem judicial (P5).

\section{DISCUSSÃO}

A discussão a seguir remete à categoria "Compreensão sobre a dificuldade de articulação dos serviços de saúde mental do município". Nessa, a maioria das participantes mostrou o desconhecimento acerca da organização dos serviços, especialmente dos CAPS AD e das Unidades de Internação. Fato este que pode ser atribuído a uma comunicação ineficiente ou inexistente entre os profissionais destes locais. Embora apresentassem essa dificuldade, demonstravam interesse em conhecer o funcionamento dos serviços de atenção, mas pouco se mobilizavam a fim de buscar conhecê-los. Destaca-se o entendimento de que a iniciativa de comunicação precisa partir da rede especializada, e não como um processo de corresponsabilização. Essa compreensão é um dos principais entraves para a composição de uma rede articulada entre os serviços de saúde e a Área de Saúde Mental, uma vez que a sua construção implica mais do que ofertas de serviços em um mesmo território geográfico. Revela a necessidade de se fomentarem questionamentos sobre como estão ocorrendo a comunicação e o relacionamento entre as equipes e serviços.

A desarticulação das ações em saúde mental no município é atribuída por algumas profissionais à falta de um fluxograma organizativo dos serviços referência em saúde mental, bem como à necessidade de apoio especializado por parte desses. Fica explícito que, embora em alguns momentos do trabalho na $A B$ tenha sido desenvolvido algum tipo de apoio especializado em saúde mental, o sentimento de incapacidade e impotência como trabalhador de saúde está presente na atuação profissional. Atribui-se a isso a dificuldade dos próprios profissionais da rede básica em acessar os serviços referência e, portanto, realizar a continuidade do cuidado.

As necessidades citadas pelas profissionais apontam para a relevância de se discutir a forma de fazer a clínica, bem como as intervenções singulares para cada sujeito. Parte-se da ideia de que o trabalho em saúde, em especial em saúde mental, solicita comprometimento e implicação com a vida das pessoas no contexto em que vivem e se relacionam.

Para o desenvolvimento do cuidado continuado e articulado em redes é necessário planejar fluxos com ações resolutivas das equipes de saúde, centradas no acolher, informar, atender e encaminhar para uma rede cuidadora. Seria um sistema de referência e contrarreferência, como um tramado de cuidados, e não com centralização numa hierarquia vertical e burocrática do uso dos recursos assistenciais, permitindo a inclusão do usuário. A fim de que este tenha conhecimento da estrutura do serviço e da rede assistencial, visando ser uma pessoa participante e influente dessa rede ${ }^{(3)}$. Destaca-se a necessidade de existir equipes de referência nos territórios, aquelas que têm a responsabilidade pela condução de um caso(11) $^{(11)}$ que venham assumir a responsabilidade pela transferência do usuário de um serviço para outro. Assim, o conceito de transferência ultrapassa o de referência e contrarreferência tradicionalmente usado, uma vez que implica em corresponsabilidade pelo usuário e garantia do acesso.

Ressalta-se que a equipe do estudo é constituída predominantemente por ACS, e essas por sua vez, não possuem núcleo profissional. Entende-se por núcleo todo o conjunto de saberes e responsabilidades específicos a cada profissão. Fato que pode corroborar para o sentimento de impotência identificado nos depoimentos, porém proporciona a circulação pelo campo profissional, saberes e práticas comuns a todos os profissionais, fato que pode trazer maior criatividade e inovação à sua prática, características fundamentais para o trabalho em saúde mental(12). Destaca-se também o papel do profissional enfermeiro como articulador da equipe de $A B$, o qual poderá acolher as demandas das ACS, contribuindo para a resolutividade dos casos e para minimizar o sofrimento dessas. 
Infere-se que a qualificação insuficiente das profissionais para trabalhar com a saúde mental na $A B$ pode resultar em dificuldades de planejamento do cuidado, bem como em se reafirmar a lógica reducionista e estigmatizadora reproduzida, muitas vezes, no cuidado ao usuário de drogas. Isso vai ao encontro de estudo, no qual foi observado que faz parte do cotidiano das equipes de referência evitar o contato com o sofrimento psíquico a partir de justificativas como a insegurança gerada pela falta de formação ou apoio em saúde mental, bem como a dificuldade em intervir para além do campo objetivo dos procedimentos e das medicações. Assim, a formação dita inadequada aparece como justificativa para a realização de encaminhamentos $^{(7)}$. Parece que, frente à subjetividade dos casos de saúde mental, a equipe da ESF estudada necessita recorrer a outro serviço para dar conta dessa demanda.

Nesse sentido, estabelecem uma relação de dependência dos serviços especializados de saúde mental, apontando que deveriam existir mais opções de serviços ou mais leitos. Essa relação dificulta a atenção aos usuários de álcool e outras drogas no cenário da $A B$, uma vez que condiciona estes profissionais aos encaminhamentos e à impossibilidade de pensar os casos e, as ações com vistas à responsabilização do cuidado. Esse é um dos diversos motivos pelos quais os profissionais da $A B$ têm dificuldade ou não prestam atendimento aos usuários portadores de transtornos mentais ${ }^{(5)}$.

O sentimento de insegurança apontado pelo grupo vai além do contato com o sofrimento, pois expressa a desproteção das profissionais pela falta de suporte teórico e técnico para desenvolver ações. É fundamental reconhecer aquilo que extrapola a formação do profissional em relação à compreensão dos processos psíquicos e aos modos de intervir nucleares da saúde mental. Para tanto, é necessária a avaliação de cada caso, em função de critérios de risco. Isso possibilitará diferenciar quais casos as equipes de referência têm competência para acompanhar de forma resolutiva e responsável ${ }^{(7)}$

Embora o sentimento de incapacidade para lidar com as situações de saúde mental, seja atribuído à falta de subsídios técnicos para as ações na $A B$, grande parte das profissionais relatou que buscava constantemente estratégias de qualificação profissional. Com isso, cabe destacar a necessidade de políticas gestoras que favoreçam os processos de qualificação das equipes e que ofereçam subsídios teóricos e metodológicos, com vistas à resolutividade das demandas de saúde mental.

Aponta-se como alternativa importante a educação permanente em saúde (EPS), definida como o processo educativo que coloca o cotidiano do trabalho, ou da formação, em saúde em análise e que possibilita construir espaços coletivos para a reflexão e avaliação de sentido dos atos produzidos no cotidiano. A EPS busca a atualização cotidiana das práticas segundo os mais recentes subsídios teóricos, metodológicos, científicos e tecnológicos disponíveis. Além de inserir-se em uma necessária construção de relações e processos que venham do interior das equipes em atuação conjunta mobilizando a instituição e o setor da saúde às práticas interinstitucionais e intersetoriais $^{(13)}$.

A incorporação do dispositivo apoio matricial (AM) para as equipes de referência é uma boa alternativa para se desenvolverem ações mais articuladas e resolutivas em saúde mental. O matriciamento em saúde visa garantir suporte especializado, tanto assistencial quanto técnicopedagógico, a equipes de referência e profissionais encarregados da atenção à problemas de saúde; procura construir e ativar espaço para comunicação e para o compartilhamento de conhecimentos entre profissionais de referência e apoiadores; personaliza os sistemas de referência e contrarreferência, ao estimular e facilitar o contato direto entre a referência encarregada do caso e o especialista de apoio(11). Segundo estudo, realizado na $A B$ em Fortaleza, o AM reorganiza a entrada do usuário nos serviços, garantindo o seu acesso ${ }^{(7)}$. Essas estratégias objetivam ampliar as possibilidades de realizar-se clínica ampliada e integração dialógica entre distintas especialidades e profissões.

Destaca-se como possibilidade o matriciamento dos CAPS para as equipes de $A B$, já que, em sua origem, os CAPS têm a função de acompanhar os usuários a partir dos territórios em que estes vivem, devendo estar articulados a outros serviços, de forma a oferecer múltiplas oportunidades de acompanhamento, tratamento, cuidado e inclusão social(14). O AM é uma possibilidade de articular o cuidado em saúde mental pela $\operatorname{ESF}^{(2)}$.

O AM traz a responsabilização compartilhada pelos casos, o que torna possível distinguir as situações que podem ser acolhidas pela equipe de referência e por outros recursos do território, daquelas que necessitam de atenção especializada. É possível evitar práticas que levem ao uso 
excessivo de medicações e de medidas de internação, além de promover a equidade e o acesso o que favorece a articulação entre os profissionais na elaboração de projetos terapêuticos singulares (PTS) ${ }^{(7)}$.

A maioria das participantes salientou que a falta de apoio em saúde mental é um empecilho para o trabalho na $A B$ e valorizou momentos de qualificação profissional, a partir das oportunidades de discussões que especialistas dos serviços de saúde mental venham desencadear, considerando esses momentos como sinalizadores de articulação entre os serviços da $A B$ e de saúde mental.

O AM em saúde mental tem potencial para proporcionar maior consistência às intervenções nessa área. Principalmente em função da questão do abuso de drogas como um problema importante de saúde pública, que ainda é incipiente na área da saúde, em especial na AB. Para tanto, os profissionais devem protagonizar uma mudança na atenção em saúde mental que começa no espaço mais restrito das relações interpessoais e interprofissionais, gerando um novo modo de organizar o processo de trabalho centrado nas demandas do território, de modo a contemplar as complexidades inerentes a este ${ }^{(12)}$.

Em sequência, a discussão é referente à categoria "Limites de acesso ao tratamento".

A não resolutividade no atendimento de saúde mental é apontada pelas respondentes por meio de depoimentos que refletem a dificuldade de acolhimento nos serviços referência e consequentemente as filas de espera. Atribuise a isso o agravamento e cronificação dos casos clínicos de saúde mental, em função da grande demanda, do número reduzido de profissionais especialistas e, portanto, do não desenvolvimento da continuidade no tratamento.

As participantes referiram recorrer a modalidades de serviços "porta-aberta", ou seja, prontos atendimentos, uma vez que esse tipo de serviço garante o atendimento imediato. Porém, parece existir uma crítica em relação ao atendimento ser condicionado às condições clínicas do usuário, já que é evidenciada a dificuldade em ser disponibilizado acesso ao serviço quando o usuário não está em crise.

No contexto do SUS, algumas estratégias e políticas vêm sendo formuladas e implantadas a fim de viabilizar a universalidade do acesso aos serviços de saúde, dentre outros princípios do SUS. Exemplo disso é a Política Nacional de Humanização, pois uma de suas prioridades é a busca pela redução das filas e do tempo de espera, por meio da ampliação do acesso e de um atendimento acolhedor, resolutivo e baseado em critérios de risco(15).

Esses achados corroboram com estudos que apontam os limites de acesso à saúde, nos quais se destacam a restrição quanto ao horário de funcionamento e o número insuficiente de vagas para consulta, indefinição dos critérios de urgência, demora na obtenção do atendimento e as filas $^{(15-16)}$. Outro fator limitante ao acesso dos usuários era o número insuficiente de profissionais na rede de saúde mental álcool e outras drogas do município. O que corrobora com estudo realizado com usuários de serviços de saúde(17) que aponta o número inadequado de profissionais para atender à demanda como determinante para a inacessibilidade ao sistema.

Embora este seja um aspecto limitador da rede de atenção em saúde mental do município, outro estudo informa que "a insuficiência de profissionais em relação à demanda é vista pelos gestores como uma dificuldade que, ao mesmo tempo, se tornou um estímulo para que as equipes de referência buscassem alternativas, tencionando assim a responsabilização"(7). No presente estudo, as participantes, expressaram que a busca por alternativas realmente acontecia, porém era entendida como sendo alternativas improvisadas que não se adequariam ao proceder em saúde mental. Além disso, outros dispositivos podem contribuir para o empoderamento dos trabalhadores de uma ESF, tais como a construção de PTS, discussão ampliada de casos entre os diferentes níveis de complexidade de atenção presente na rede local de saúde.

Outro aspecto do acesso dos usuários ao tratamento na rede local de saúde é a não garantia igualitária deste pelo Estado, especialmente em clínicas de recuperação para usuários de álcool e outras drogas. As participantes expressaram que há dois aspectos relativos a isto: a garantia somente por medidas judiciais e a dificuldade de acesso para as classes econômicas menos favorecidas. Além disso, falam da complexidade que é pensar ações no contexto do abuso do álcool e outras drogas. Elas percebiam a premência de discutirem os profissionais da rede básica com profissionais especializados.

Percebe-se dessa forma a dificuldade da $A B$ em acolher as demandas dos usuários de álcool e outras drogas, além da dificuldade em trabalhar com a família dessas pessoas. Em um estudo realizado sobre a prática de cuidados relacionados ao abuso e dependência de drogas no cotidiano de uma equipe de ESF, foram encontrados significativos 
problemas relacionados ao uso de substâncias que se estendem além das questões individuais, aos familiares e à comunidade. Assim, a prática de cuidados relacionados ao abuso de drogas na ESF necessita priorizar medidas seletivas de prevenção primária por meio de ações de promoção da saúde, envolvendo o sujeito, as famílias, os grupos e a comunidade na criação de condições de redução da demanda de oferta de drogas ${ }^{(6)}$. Ressalta-se que a família deve ser incluída como principal parceira no processo terapêutico, e deve ser instrumentalizada pela equipe de saúde a partir de suas necessidades específicas, por meio de visitas domiciliares, grupo para familiares, entre outros recursos.

A questão do acesso necessita ser constantemente abordada nos espaços da saúde e é importante que o gestor local seja o mediador e mobilizador da discussão. Porém, para superar os limites é preciso ir além das discussões. $O$ tema do acesso aos serviços de saúde precisa estar presente nos planejamentos em saúde, de forma local, a fim de assegurar a definição de ações consonantes com as realidades comunitárias. As políticas nacionais poderão direcionar o planejamento, mas cabe a todos os envolvidos nos contextos locais pensar e estabelecer melhores formas de acesso, de acordo com as necessidades da população(17).

Reforça-se a necessidade de abordar o tema do uso abusivo de drogas, a partir de ações na comunidade, grupos de apoio, entre outros dispositivos direcionados a usuários e/ou familiares. Esses espaços poderiam contar com o apoio matricial das equipes de especialistas dos diferentes pontos da rede e de profissionais residentes. Desse modo, poderiam estar se construindo movimentos de ruptura do modelo tradicional, individual e especializado de atenção à saúde.

\section{CONSIDERAÇÕES FINAIS}

A contribuição das profissionais do estudo está na produção de dados sobre a articulação da rede de atenção em saúde mental a usuários de álcool e outras drogas, bem como os limites do acesso a esta e a necessidade de qualificação profissional para o trabalho em rede de atenção nesta área. Compreende-se que a desarticulação dos serviços de saúde mental permeia o entendimento das profissionais, sendo que a maior parte delas atribui a desarticulação à falta de um fluxograma organizativo dos serviços, e à necessidade de apoio matricial para o trabalho de saúde mental na atenção básica.
A falta de comunicação entre os serviços e o desconhecimento sobre a dinâmica de funcionamento destes é um fator limitante à composição de uma rede de atenção, bem como ao acesso pelos usuários. Como principal possibilidade para suprir tais necessidades é apontado o apoio matricial. As barreiras para o acesso dos usuários aos serviços são determinadas pela insuficiência de profissionais especializados. Resultando em dificuldades dos serviços em acolher os usuários e, consequentemente, a formação de filas, agravando assim os casos de saúde mental. Ressalta-se ainda a limitação do Estado, por meio do Sistema Único de Saúde, em garantir o acesso igualitário ao tratamento.

A busca espontânea por qualificação profissional é atribuída às demandas geradas a partir da não resolutividade dos serviços da rede de saúde mental. Ademais, a insuficiente qualificação para o trabalho em rede de atenção em saúde mental sinaliza limitações para atuar, conforme os pressupostos e diretrizes da atual Política sobre Drogas. Isso poderá resultar em dificuldades de planejamento do cuidado, bem como reafirmar a lógica reducionista e estigmatizadora (re)produzida, muitas vezes, no cuidado ao usuário de drogas. O que reafirma a dependência destas profissionais dos encaminhamentos aos serviços especializados, reforçando a dificuldade dos serviços de saúde trabalharem em rede.

Destaca-se a necessidade de se criar estratégias e dispositivos de gestão, atenção e formação em saúde que possam impactar na forma de os serviços se articularem em rede, aumentando seu sistema comunicacional. Uma dessas possibilidades é o apoio matricial para as equipes das ESFs, por meio da integração ensino-serviço dos Programas de Residências Multiprofissionais, no campo da saúde mental, com as equipes de atenção básica.

Também, aponta-se a importância do envolvimento dos trabalhadores nos processos decisórios do trabalho, a fim de possibilitar a ressignificação de suas práticas na busca de uma construção cotidiana deste trabalho, frente ao desafio de consolidar e fortalecer uma rede e atenção à saúde mental, capaz de promover acolhimento e vínculo terapêutico, ofertar um tratamento que propicie a autonomia do usuário. Neste cenário, apontam-se desafios aos trabalhadores.

Observa-se, assim, a premência de serem realizadas discussões tanto na academia, pois esta, ainda, mostra-se distante dos cenários de atuação, especialmente das 
políticas públicas, como no setor de saúde, com gestores e profissionais, acerca da temática em questão, bem como suas repercussões na saúde dos usuários dos serviços de saúde mental, uma vez que a Política sobre Drogas apresenta suas ações embasadas no caráter de rede de atenção e pautadas na diretriz de redução de danos.

Acredita-se que repensar as práticas de cuidado de modo a (re)organizar a maneira como os serviços se estruturam e a fim de compor uma rede de atenção e

\section{REFERÊNCIAS}

1. Ministério da Saúde. Coordenação Nacional de DST e AIDS. Política de Atenção Integral a Usuários de Álcool e Outras Drogas. Série B. Textos Básicos de Saúde. Brasília (Brasil): Ministério da Saúde, 2003. $60 \mathrm{p}$.

2. Silva $C B$, Santos JE, Souza RC. Estratégia de Apoio em Saúde Mental aos Agentes Comunitários de Saúde de Salvador-BA. Saude soc. [internet] 2012 [cited 2012 ago 10];21(1):153-160. Available from:

http://www.scielo.br/scielo.php?pid=S0104$12902012000100015 \&$ script $=$ sci arttext

3. Ceccim RB, FERLA AA. Linha de cuidado: a imagem da mandala na gestão em rede de práticas cuidadoras para uma outra educação dos profissionais de saúde. In: Pinheiro R, Mattos RA, editors. Gestão em redes: práticas de avaliação, formação e participação na saúde. Rio de Janeiro: CEPESC; 2006. p. 165-184.

4. Lancetti A, Amarante P. Saúde Mental e Saúde Coletiva. In: Campos, GW de S, editors. Tratado de Saúde Coletiva. São Paulo: HUCITEC; 2009. p. 616-634.

5. Morais APP, Tanaka OY. Apoio Matricial em Saúde Mental: alcances e limites na atenção básica. Saude soc. [internet] 2012 [cited 2012 ago 10];21(1):161-170. Available from:

http://www.scielo.br/scielo.php?pid=S0104-

$12902012000100016 \&$ script $=$ sci arttext

6. Barros MA, Pillon SC. Programa Saúde da Família: desafios e potencialidades frente ao uso de drogas. Rev. Eletr. Enf. [internet] 2006 [cited 2012 ago 10];8(1):144-149. Available from: http://www.revistas.ufg.br/index.php/fen/article/view/932/1129

7. Figueiredo MD, Campos RO. Saúde Mental na atenção básica à saúde de Campinas, SP: uma rede ou um emaranhado? Cien Saude Colet. [internet] 2009 [cited 2012 ago 10];14(1):129-138. Available from: http://www.scielo.br/pdf/csc/v14n1/a18v14n1.pdf

8. Ribeiro JM, Inglez-Dias, A. Políticas e inovação em atenção à saúde mental: limites ao descolamento do desempenho do SUS. Cien Saude Colet. [internet] 2011 [cited 2012 ago 10];16(12):46234633. Available from: http://www.scielo.br/pdf/csc/v16n12/11.pdf 9. Minayo MC de S. O desafio do conhecimento: pesquisa qualitativa em saúde. 12a ed. São Paulo: HUCITEC; 2010. 407 p.

10. WestphaL MF, Bógus CM, Faria MM. Grupos Focais: experiências precursoras em programas educativos em saúde no Brasil. Boletín de la Oficina Sanitaria Panamericana. [internet] 1996 [cited 2012 mar 03]; 120(6):472-481. Available from: http://hist.library.paho.org/Spanish/BOL/v120n6p472.pdf.

11. Campos GW de S, Domitti AC. Apoio matricial e equipe de referência: uma metodologia para gestão do trabalho interdisciplinar em saúde. Cad Saude Publica. [internet] 2007 [cited 2012 jul 05]; 23(2):399- 407.4 Available from: http://www.scielo.br/pdf/csp/v23n2/16.pdf.

12. Pinho LB, Rodrigues J, Kantorski LP, Olschowsky A, Schneider JF. Desafios da prática em saúde mental na perspectiva do modo psicossocial: visão de profissionais de saúde. Rev. Eletr. Enf. garantir o acesso aos usuários do SUS seja urgente. Do contrário, a construção de competências alinhadas às políticas públicas e a garantia de atendimento humano e integral ficarão somente no campo do debate. Recomendase, assim, o desenvolvimento de outros estudos multiprofissionais que criem nexos entre a rede de atenção a usuários de álcool e outras drogas, e o processo de educação dos profissionais, entrelaçando-o com o processo de cuidar em saúde mental.

[internet] 2012 [cited 2012 ago 10]; 14(1): 25-32. Available from: http://www.fen.ufg.br/fen revista/v14/n1/pdf/v14n1a03.pdf.

13. Ceccim RB. Educação Permanente em Saúde: desafio ambicioso e necessário. Interface - Comunic., Saude, Educ. [internet] 2005; [cited 2012 ago 10]; 9(16): 161-77. Available from: http://www.escoladesaude.pr.gov.br/arquivos/File/textos\%20eps/e ducacaopermanente.pdf

14. Pinho LB, Hernández AMB, Kantorski LP. Serviços substitutivos de saúde mental e inclusão no território: contradições e potencialidades. Cien Cuid Saude. [internet] 2010 [cited 2012 jul 05]; 9(1): 28-35. Available from: http://periodicos.uem.br/ojs/index.php/CiencCuidSaude/article/vie w/6824/5733

15. Nonnenmacher $\mathrm{CL}$, Weiller $\mathrm{TH}$, Oliveira SG. Acesso à saúde: limites vivenciados por usuários do SUS na obtenção de um direito. Cien Cuid Saude. [internet] 2011 [cited 2012 jul 05]; 10(2):248$255 . \quad$ Available from: http://periodicos.uem.br/ojs/index.php/CiencCuidSaude/article/vie w/10106/pdf

16. Oliveira LH, Mattos RA, Souza AIS. Cidadãos peregrinos: os "usuários" do SUS e os significados de sua demanda a prontossocorros e hospitais no contexto de um processo de reorientação do modelo assistencial. Cien Saude Colet [Internet] 2009 [cited 2012 jul 05]; 14(5):1929-1938. Available from: http://www.scielo.br/pdf/csc/v14n5/35.pdf

17. Souza ECF et al. Acesso e acolhimento na atenção básica: uma análise da percepção dos usuários e profissionais de saúde. Cad Saude Publica [internet] 2008 [cited 2012 jul 05]; 24(1):100-110. Available from: http://www.scielo.br/pdf/csp/v24s1/15.pdf.

Artigo recebido em 24/09/12.

Aprovado para publicação em 09/10/13.

Artigo publicado em 31/03/2014. 